\title{
Community Genetics in India- A Public Health Issue Rarely Explored
}

\author{
${ }^{1}$ State Surveillance Officer, Directorate of Health Services, India \\ ${ }^{2}$ Director Health Services, India \\ ${ }^{3}$ Public Health Expert, Germany \\ ${ }^{4}$ Public Health Professional, Member American Public Health Association, USA \\ ${ }^{5}$ Physician Researcher and Global Health Scientist, USA \\ ${ }^{6}$ Indian Institute of Public Health, India
}

Kadri SM${ }^{1 *}$, Felipe Weinberg ${ }^{2}$, Saleem ur Rehman ${ }^{3}$, Aijaz Lubna ${ }^{4}$, Jenevieve S Kincaid ${ }^{5}$ and Mahnoor Kadri ${ }^{6}$

Submission: April 21, 2017; Published: May 25, 2017

*Corresponding author: Kadri SM, Division of Epidemiology and Public Health, RFPTC Building, Barzulla, Srinagar 190005, Kashmir, India, Email: kadrism@gmail.com

\begin{abstract}
Objective: The greatest breakthroughs in human genetics provide significant promise for improving Public Health. Community genetics is the public health aspect of genetic science responsible for creating realistic applications of the advances in treating genetic disease. These advances could greatly improve individual as well as general public health. The right intervention and policies gives India has the potential to resolve many community genetic problems.

Background: The accessibility of community genetic services in developing countries, especially in India, is insufficient. India's public health issues are exacerbated by: its large population, and the low availability and accessibility of resources. Other significant problems include: high birth rate, the advanced age at which women continue to conceive and endogamy. The widespread incident of exposure to teratogens increases the risk for birth defects and genetic diseases precipitated by the exposure. These teratogenic incidences require immediate attention and control. It is therefore essential that community based interventions include the three core functions of public health which include assessment, policy development, and assurance. The core functions are reinforced and preventive strategies at primary, secondary and tertiary health-care levels.
\end{abstract}

Methods: Secondary data was accessed through Pub Med and Scholarly reviews. The review reflected the oversight of the notion of community genetics and associated problems in India based on the consanguineous marriages and genetic disease database. The databases included genetic services and framework for community control, as well as chromosomal abnormalities as genetic diseases increase the burden in India.

Results: There is a high prevalence of genetic disorders due to the custom of consanguineous marriages in several communities of India. The rate of ancestral marriages is as low as $1 \%$ to $4 \%$ in the northern region, but as high as $40-50 \%$ in the southern region specifically among Muslims [1].

Conclusion: The three core of public health functions; assessment, policy development and assurance that includes training of health professionals, public education, clinical detection of congenital disorders, new-born screening should be reinforced. Valid epidemiologic data collection, necessary evaluation, analysis, political will and resources are needed for emphasis on establishing planning, prevention and intervention strategies for congenital disorders and genetic diseases.

Keywords: Community genetics; Congenital disorders; Birth defects; Public health genetics; India

\section{Introduction}

In the past few decades, the technological advances and development in human genetics have provided great commitments for improving Public Health. Genetics has been declared by some as the new rebellion in health care [2]. The new developments in genetics are already impacting society's health in numerous ways. With the passage of time, health care providers should advance information about innovative 
discoveries in terms of chronic diseases and genetic disorders, thereby predicting and promoting concepts for better health services [3]. The new genetic approach attempts to elucidate formerly unknown genetic and phenotypic variance and striving to resolve the complex synergy between genes and environment, by applying new statistical modeling methods and techniques [4].

The term "public health genetics" has been introduced to denote the interface between genetics and public health, and is used in titles of training courses and names of research groups. It reflects attempts by the public health profession to cope with, and make best use of the rapid advances in genetics. Genetic tests can, for example, be used in screening programs for disease or for directing health promotion interventions. "Community genetics", on the other hand, indicates attempts by clinical geneticists to apply their counselling methods to the whole population [5].

Community genetics has also been defined as "the art and science of the responsible and realistic application of health and disease-related genetics and genomics knowledge and technologies in human populations (communities) to the benefit of individual persons" [6]. The goal is to prevent congenital disorders and genetic diseases at the population level and at the same time provide genetics services (diagnosis and counselling) in the community for individuals and families. The Public Health aspect narrates population health promotion as a whole and the decrease of the prevalence of congenital disorders and genetic diseases, while honoring the rights of individuals to make unmonitored decisions in health and reproductive matters without compulsion of any kind and from any source [7].

The availability of community genetic services in developing countries and especially in India is less than adequate, in that genetic services at community level are usually planned and implemented by the public health sector of the State. This may be due to a number of reasons: paucity of resources; genetic conditions not being considered priorities; misconceptions that the control of common congenital disorders is too expensive and linked with sophisticated technology; low genetics literacy; cultural, legal and religious limitations such as the fear of stigmatization within the community and the legal or religious restrictions to selective abortion of affected foetuses; an insufficient number of trained health professionals; and inadequate data on the true magnitude and economic burden of congenital disorders $[7,8]$. Congenital disorders (birth defects) constitute a major health problem worldwide, especially in developing countries. Factors that may contribute to the high rates of congenital disorders in such countries include lack of availability of public health resources directed at the care and prevention of these disorders [7].

The high frequency of haemoglobinopathies in Africa, the Middle-East and South-East Asia, and the high consanguinity rates in the Eastern Mediterranean and South-East Asia regions that increase the occurrence of recessively inherited diseases, can be attributed to: the advanced maternal age at conception in developing countries, which increases the predisposition to chromosomal trisomies such as Down syndrome, and large family size, which may increase the number of affected children in families with autosomal recessive conditions [3].

Especially in India, where the population of 1.27 billion comprises about one-sixth of the world's inhabitants, the large family sizes in rural areas [9] and the contemporary social structure of Indian populations is characterized by endogamy with different degrees of porosity [10]. This provides a unique resource for dissecting complex disease etiology and pathogenesis. Further, India has a fertility rate of 2.5 , and a declining infant mortality rate of 41 per 1000 live births, as per an estimate by the World Bank in 2012 [11,12]. With the growing population and high rate of ancestral marriages prevailing in some States, India is a hotspot for studying genetic defects [13]. The objective of this study is to analyze the rates of common congenital and genetic disorders and the accessible community genetic services in India, and examine the key characteristics that contribute to this prevalence and explore the current impediments that are limiting community genetic services.

\section{Methods}

This study is an analysis of secondary data accessed through PubMed and Scholar reviews. It provides an overview of conception of community genetics and the genetic related problems in India. Scholarly articles assessed based on consanguineous marriage and human evolution, Indian genetic disease database, genetic services and framework for community control, implications of the human genome, and chromosomal abnormalities as genetic disease burden in India, report of World Health Organization consultation on community genetics in developing countries. Implications and ideas have been cited from various studies relevant to community genetics in India enhancing the validation of our study. Search terms used: India, community genetic, congenital disorders, birth defects and public health genetic.

\section{Results}

\section{Common congenital and genetic disorders in India}

India has large population, which is ever-growing due to the high birth rate, as signified by a growth rate of $1.6 \%$ according to the 2011 census [14]. Due to many cases of consanguineous marriages, which are a tradition in many communities, there is a high prevalence of genetic disorders in the country.

The rate of consanguineous marriages according to the following facts (Table $1 \& 2$ ) [1], is as low as $1 \%$ to $4 \%$ in the northern region, but as high as $40-50 \%$ in the southern region. Table 1 illustrates consanguineous marriages among various religious groups in India; according to which Muslims has highest rate of 23.3 followed by Buddhist 17.1, whereas Christians 


\section{Global Journal of Intellectual \& Developmental Disabilities}

and Hindus has comparatively low rates of 10.3 and 10.7 respectively. However, it was found out that such marriages were lowest amongst Sikh with the rate of 1.5. Simultaneously Table 2 illustrates rate of consanguineous marriages in several States of India classified in different regions. It is therefore apparent that Table 1: Rate of consanguineous marriages among various religious groups in India [1]

\begin{tabular}{|c|c|c|}
\hline Religion & Consanguineous Marriage (\%) & Mean Coefficient of Inbreeding (A) \\
\hline Hindu & 10.6 & 0.0068 \\
\hline Muslim & 23.3 & 0.0141 \\
\hline Christian & 10.3 & 0.0068 \\
\hline Sikh & 1.5 & 0.0009 \\
\hline Jain & 4.3 & 0.0024 \\
\hline Buddhist & 17.1 & 0.0107 \\
\hline Others & 8.7 & 0.0053 \\
\hline
\end{tabular}

Table 2: Rate of consanguineous marriages in several States of India classified with different Regions respectively [1].

\begin{tabular}{|c|c|c|c|}
\hline Region & State & Consanguineous Marriage (\%) & $\begin{array}{l}\text { Mean Coefficient of Inbreeding } \\
\text { (A) }\end{array}$ \\
\hline \multirow[t]{6}{*}{ North } & 1.Delhi & 4,3 & 0,0023 \\
\hline & 2.Haryana & 1,0 & 0,0004 \\
\hline & 3.Himachal Pradesh & 0,8 & 0,0003 \\
\hline & 4.Jammu and Kashmir* & 8,0 & 0,0049 \\
\hline & 5.Punjab & 0,9 & 0,0006 \\
\hline & 6.Rajasthan & 1,3 & 0,0006 \\
\hline \multirow[t]{2}{*}{ Central } & 7.Madhya Pradesh & 4,1 & 0,0025 \\
\hline & 8.Uttar Pradesh & 7,5 & 0,0044 \\
\hline \multirow[t]{3}{*}{ East } & 9.Bihar & 5,0 & 0,0032 \\
\hline & 10.Orissa & 5,7 & 0,0035 \\
\hline & 11.West Bengal & 5,0 & 0,0030 \\
\hline \multirow[t]{7}{*}{ Northeast } & 12.Arunachal Pradesh & 3,9 & 0,0029 \\
\hline & 13.Assam & 1,7 & 0,0010 \\
\hline & 14.Manipur & 2,1 & 0,0013 \\
\hline & 15.Meghalaya & 2,7 & 0,0018 \\
\hline & 16.Mizoram & 0,5 & 0,0002 \\
\hline & 17.Nagaland & 1,5 & 0,0009 \\
\hline & 18.Tripura & 1,9 & 0,0010 \\
\hline \multirow[t]{3}{*}{ West } & 19.Goa & 10,6 & 0,0066 \\
\hline & 20.Gujarat & 4,9 & 0,0029 \\
\hline & 21.Maharashtra & 21,0 & 0,0131 \\
\hline \multirow[t]{3}{*}{ South } & 22.Andhra Pradesh & 30,8 & 0,0212 \\
\hline & 23.Karnataka & 29,7 & 0,0180 \\
\hline & 24.Kerala & 7,5 & 0,0042 \\
\hline All-India & & 11,9 & 0,0075 \\
\hline & ${ }^{*}$ Data was colle & ly in Jammu region. & \\
\hline
\end{tabular}

In a report by Bittles 2002, the rate of consanguineous marriage in India was discussed in detail, with the southern region showing the highest rate and, among various religious sects; Muslims had the highest rate of consanguineous marriage. These higher rate being influenced by an old tradition of marriages between uncle-niece and first-cousin marriages such marriages are more widespread in North and Northeast regions with low rates as compared to South and West regions where this pattern is confined to three States respectively but with higher rates [1]. 
Congenital malformations and genetic disease contributes to high incidence of mortality and morbidity in the cities of India. The most common congenital and genetic disorders in India are Down's syndrome, thalassemia, haemophilia, muscular dystrophy, sickle cell anaemia and amino acid disorders. Among congenital disorders, heart defects and neural tube defects, apart from Down's syndrome, are the most common disorders in India as seen in Table 3 [16].

Recent study in Madhya Pradesh State of India, of 107 carrier couples of $\beta$-thalassemia 35 and sickle cell anemia 72 with progenies who are affected with the disease, it was found that the maternal distance is indirectly proportional to the risk of the recessive genes being expressed. Majority of the carrier couples who had affected offspring had married within close physical distance of a radius less than $50 \mathrm{kms}$. The closer the distance between parents, the higher the chances of cases such as stillbirths, neonate mortality, infant mortality. This relates to the chances of inbreeding or homozygosis leading to expression of recessive genes, which otherwise remains silent [17].

Another study in Central India on congenital birth defects concluded that $1.91 \%$ of live births were affected within the study period of 3 years, during which 9386 deliveries were accounted for malformations were congenital, observed more frequently in stillbirths, with a high degree of significance. With an increase in age of the mother, there were higher chances of congenital malformations of the child. Among the type of birth defects, cardiovascular malformations were most common, followed by musculoskeletal malformations among live births. However, among stillbirths CNS defects were most common [18,19].

Congenital malformations and genetic defects also attributed to the incidence of exposure to teratogens. It has been found that in terms of exposures to teratogens before and after conception, $11 \%$ of reproductive age group females were using any form of tobacco and its usage was almost equal among pregnant and non-pregnant women. Children of women who smoke during pregnancy are found to be 1.5-2 times more likely to have multiple birth defects [20]. Exposures to other categories of drugs during their first trimester varied from $55.28 \%$ for category A to $6 \%$ for category D drugs respectively. Moreover, easy availability of drugs, coupled with inadequate health services, compound the problem of intake of non-prescribed drugs and self-medication [21].

In order to establish a thorough knowledgeand understanding of the genetic diseases in the Indian population, the Indian Genetic Disease Database (IGDD), an initiative of CSIR and IICB, was established in 2010. The database features a thorough update of the patient database, as well as the features of the disease. IGDD aims to keep up-to-date data about mutations seen in India and help community genetic services and physicians, as well as other individuals, seeking information to retrieve and use the knowledge available. The database is a reference for the entire Indian population with specifications available for genetic disorder load in specified populations.

Curation and submission of new and already identified mutations and genetic disorders can be processed through email to the curator or can also be submitted through an online portal. However, the submission of new incidences should be supported by publication in peer-reviewed journals so that the data is authenticated and reliable for reference. Currently the IGDD features 52 types of genetic diseases or syndromes, among which 51 are known to have an inheritance pattern. Autosomal dominant disorders are 12 in number, with 29 autosomal recessive, $1 \mathrm{X}$-linked dominant, $6 \mathrm{X}$-linked recessive, along with no known Y-linked inheritance incidence in India. Among all the genetic disorders, $\beta$-thalassemia remains the most prevalent disease [22]. However, a large section of the population still remains unable to access regular hospital or institutional deliveries, which further leads to the fact that the data compiled is still incomplete and there is likely to be the higher incidence of such abnormalities in India if the whole population is taken into account.

\section{The community genetic services in India}

India, with its large population, faces high incidence of genetic disorders and needs immediate attention in order for it to be controlled. Genetic diseases and congenital abnormalities can cause considerable loss to the society, therefore its effective management should be considered immediately. The problem is further augmented due to limitations in diagnostic methods, as well as a lack of rehabilitation facilities. Although the Government of India has provided liberal research funding on these diseases, very little knowledge and attention has been received in this context. Therefore, community based intervention and genetic service becomes a necessity.

As per the approval of a resolution about prevention and management of birth defects by the World Health Organization (WHO) in May 2010 on community genetic services in low- and middle-income countries, the genetic services should be more accessible to the general public. Community genetic service works with the sole aim of providing diagnosis and counselling of common genetic disorders in the community, as well as preventing the occurrence of the diseases [23].

In the Indian scenario it can be noted that the community genetic services is yet to be practical, as there are still no proper guidelines available for best practice genetic counselling. Trained genetic counsellors or courses and even diagnostic centres to test abnormalities are still very few in numbers. According to Genetics India, a service funded by ICMR, which maintains a database of genetic diagnostics and counselling services in India, there are 26 genetic counselling centres and limited numbers of diagnostic centres, which are so unevenly distributed that 
states such as Karnataka have more than 10 diagnostic centres while Uttar Pradesh has less than 5 centres. Some states such as Manipur do not have either a counselling centre or a diagnostic centre (Genetic India, 2014). Though research in the field is advancing, there are still no authorities or accreditation bodies that can set guidelines or impose best-practice in genetic testing laboratories [24,25].

The importance of genetic counselling is reflected by an ICMR-funded study conducted in five district hospitals. Out of 8331 pregnant women screened, 1167 (14\%) were at risk of having unwanted pregnancy outcomes. Since foetal wastage and congenital malformations are major outcomes of genetic abnormalities, screening of pregnant women for such conditions is essential. Out of the various factors, screened neural tube disorders and congenital malformations were presented to be the highest risk leading to fetal wastage. Unwanted outcomes in previous pregnancy also play a major role in the success of subsequent pregnancies. Further analysis found a number of shortcomings that proved to be detrimental for the studies, such as loss of contact with the patient or their family members, as well as increased workload on the screening team that lead to subsequent termination of the screening program.

The study further concluded that hurdles such as a lack of proper facilities and infrastructure, travelling logistics and untraceable lineage contributed to hardships in the studies. It was further recommended that incorporation of genetic counselling and genetic services in the existing health missions, as well as health centres, are necessary, as more than $75 \%$ of the population of India is in the rural areas [8].

\section{Discussion}

\section{Why is a high prevalence?}

Factors that could contribute to the high rates of congenital disorders are:

a) General Low availability of public health measures directed at the care and prevention of congenital disorders and the dearth of genetic services and inadequate health care prior to and during pregnancy.

b) Advanced age to which women continue to conceive, which increases the predisposition to chromosomal trisomies such as Down syndrome (related to advanced maternal age). Further, advanced paternal age increases the risk of occurrence of new mutations, causing certain autosomal dominant disorders. Although the average maternal age is 19 years when the first child is born, childbirth continues till an advanced maternal age. It has been further observed that advanced maternal age of grandmothers can significantly contribute to the chances of having a child with Down syndrome.

c) Large family sizes (an average of 4.8), and a high level of endogamy, where consanguinity marriage rates varies from as low as $1 \%$ to $4 \%$ in the northern region to as high as 40 $50 \%$ in the southern region [1], contributes to the increase in the number of affected children in families with autosomal recessive conditions.

d) Exposure to teratogens is another factor that is contributing to the high prevalence of genetic disease.

\section{Why are current impediments?}

Reliable epidemiologic and burden-of-disease data collection and needs-assessment analysis are needed to focus on priorities in planning care and prevention programmes for congenital disorders and genetic diseases. Data on the extent and availability of community genetics services, manpower, and laboratory facilities in countries should be obtained. Political will and commitment and financial resources are needed for funding and planning programmes for the care and prevention of congenital and genetic disorders.

\section{Conclusion}

The three core public health functions and genetics [3] should be reinforced:

A. Assessment: It is necessary to regularly collect, analyze, and share information, including genetic information and environmental interactions related to health conditions, risks, and community resources. This surveillance is needed to determine the population frequency of genetic variants that predispose people to specific diseases, both common and rare. This information is necessary for State health officials and others responsible for providing health policy guidance, to enact policies and programs that are best for their communities. This involves establishing clear and measurable objectives and to determine the most efficient interventions to achieve the specific goals.

B. Policy development: Stronger public health policies needed to provide better information to members of the public, with objective guidance to empower them in decision making regarding the use of genetic technologies. Issues such as health insurance discrimination, population screening and privacy and confidentiality need to be addressed to ensure the public's health and minimize potential harm.

C. Assurance: A better collaboration between agencies, public and private entities is needed. It is necessary to educate public health staff and private healthcare workers about the use of genetic information to improve health. Programmatically, the incorporation of up-to-date genetic information in areas such as maternal and child health, occupational health and disease prevention programs will improve outcomes by providing better prevention information. This information should be available in formats that are appropriate to the target audience in terms of reading level and cultural competence. 
The services required for the prevention and care of congenital disorders and genetic diseases include prevention strategies at primary, secondary and tertiary health-care levels, as shown in Table $2 \& 4$. In relation to determining the most efficient interventions, experience and examples from different countries indicate that the most common genetic services at community level (i.e. "minimum package of interventions") are: Training health professionals in basic concepts of genetics and their application to community genetics services such as: how to use family history as an instrument to detect genetic risks; the pre-conception and prenatal care, including folic acid fortification or supplementation; addressing the genetic risks of maternal age and consanguinity; genetic counselling when needed; prenatal ultrasound screening to detect foetal abnormalities; and referring detected genetic problems to a tertiary centre for proper management. This involves:

a) Public education to avoid alcohol, tobacco and potential teratogens in gestation.

b) Clinical detection of congenital disorders in newborns and appropriate referrals to higher levels of care for diagnosis and treatment.

c) New-born screening for congenital conditions in which early intervention is effective, such as congenital hypothyroidism, followed by treatment and other services for life.

With the right intervention and policies, India has a great potential to tackle community genetic problems.

\section{Reference}

1. Bittles A, Black M (2010) Consanguineous marriage and human evolution. Annual Review of Anthropology 39: 193-207.

2. Collins FS, Mckusick VA (2001) Implications of the Human Genome Project for medical science. JAMH 285(5) 540-544.

3. Aswini Y, Varun S (2010) Genetics in public health: Rarely explored Indian J Hum Genet 16(2): 47-54.

4. Townsend GC, Aldred MJ, Bartold PM (1998) Genetic aspects of dental disorders. Aust Dent J 43(4): 269-86.

5. Mackenbach JP (2005) Community genetics or public health genetics? J Epidemiol Community Health 59(3): 179-180.

6. Ten Kate LP, Al-Gazali L, Anand S, Bittles A, Cassiman JJ, et al. (2010) Community genetics. Its definition 2010. J Community Genet 1(1): 1922.

7. World Health Organization (2011) Community genetics services: report of a WHO consultation on community genetics in low-and middle-income countries. Switzerland, p. 1-38.

8. Agarwal S (2009) Feasibility of introducing genetic services in the National Family Welfare Programme in India. Indian J Med Res 130(4): 404-412.

9. Gentic India (2014) Genetic Counselling, India.

10. Majumder PP, Basu A (2014) A Genomic View of the Peopling and Population Structure of India. Cold Spring Harb Perspect Biol 7(4): a008540.

11. CIA (2014) Fertility rate, total (births per woman). The World Bank, USA.

12. World Bank (2014) Mortality rate, infant (per 1,000 live births). The World Bank, USA.

13. Dixit S, Sahu P, Kar SK, Negi S (2015) Identification of the hot-spot areas for sickle cell disease using cord blood screening at a district hospital: an Indian perspective. J Community Genet 6(4): 383-387.

14. Bongaarts J, Sinding S (2011) Population policy in transition in the developing world. Science 333(6042): 574-576.

15. Sastri KAN (1976) A History of South India: from Prehistoric Times to the Fall of Vijayanagar. ( $4^{\text {th }}$ edn), Oxford University Press, India, p. 66.

16. Verma IC (2000) Burden of genetic disorders in India. Indian J Pediatr 67(12): 893-898.

17. Balgir RS (2013) Contribution of marital distance to community inbreeding, homozygosis, and reproductive wastage for recessively inherited genetic disorders in madhya pradesh, India. Mediterr J Hematol Infect Dis 5(1): e2013063.

18. Taksande A, Vilhekar K, Chaturvedi P, Jain M (2010) congenital malformations at birth in Central India: A rural medical college hospital based data. Indian J Hum Genet 16(3):159-163.

19. Kaur A, Singh JR (2010) Chromosomal abnormalities: genetic disease burden in India. Int J Hum Genet 10(1-13): 1-14.

20. Kälèn K (2000) Multiple malformations and maternal smoking. Paediatric and perinatal epidemiology 14(3): 227-233.

21. Sharma R, Verma U, Sharma C, Kapoor B (2005) Self-medication among urban population of Jammu city. Indian journal of pharmacology 37(1): 40-43.

22. Pradhan S, Sengupta M, Dutta A, Bhattacharyya K, Bag SK, et al. (2011) Indian genetic disease database. Nucleic Acids Res 39(Database issue): D933-D938.

23. World Health Organization (2012) Screening the gene. Switzerland.

24. Verma IC, Bijarnia S (2002) The burden of genetic disorders in India and a framework for community control. Community Genet 5(3): 192196.

25. International Institute for Population Sciences (IIPS) and Macro International (2007) In: Mari Bhat PN (Eds.), National Family Health Survey (NFHS-3), 2005-06. India, pp. 1-519. 
This work is licensed under Creative Commons Attribution 4.0 Licens

DOI: 10.19080/GJIDD.2017.01.555563
Your next submission with Juniper Publishers will reach you the below assets

- Quality Editorial service

- Swift Peer Review

- Reprints availability

- E-prints Service

- Manuscript Podcast for convenient understanding

- Global attainment for your research

- Manuscript accessibility in different formats

( Pdf, E-pub, Full Text, Audio)

- Unceasing customer service

Track the below URL for one-step submission https://juniperpublishers.com/online-submission.php 